\title{
Molecular Interaction between a Bcl-2 Homolog from Kaposi Sarcoma Virus and p53
}

\author{
Ji-Hyang Ha, ${ }^{\dagger, a}$ Eun-Young Won, ${ }^{a}$ Ho Sup Yoon, ${ }^{\ddagger}$ Sunghyun Kang, Kwang-Hee Bae, Sung Goo Park, \\ Byoung Chul Park, Byong-Seok Choi, Joon-Hwa Lee, ${ }^{\ddagger}-{ }^{\S}$ and Seung-Wook Chi \\ Medical Proteomics Research Center, KRIBB, Daejeon 305-806. Korea. ${ }^{*}$ E-mail: swchiáakribb.re.kr \\ Department of Chemistry, RINS, Enironmental Biotechology National Core Research Center. \\ Gyeongsang National inversity, Jinju, Gveongnam 660-701, Korea. ${ }^{*}$-mail: joonhwagigntackr \\ Eivision of Structural and Computational Biologv: School of Biological Sciences, Nanvang Technological Lniversitn, \\ 60 Nanvang Drive, Singapore 637511, Singapore \\ Deparment of Chemistry and National Creative Research Initiative Cemer, KHIST, Daejeon 305-701. Korea \\ Received February 11, 2009, Accepted Hav 15, 2009
}

Key Wonds: KSHV Bcl-2, p53. NMR. HSQC, Molecular interaction

Many viruses have anti-apoptotic proteins to prevent apoptotic defense mechanism of virus-infected host cells. Since $\mathrm{Bcl}-2$ family proteins are key players in the regulation of apoptosis. the homologs of $\mathrm{Bcl}-2$ with stnictural and functional similarity are expressed by viruses such as Kaposi sarcomaassociated herpes virus (KSHV), adenovinis. and EpsteinBarr virus (EBV). For example, Kaposi sarcoma tumor-causing virus KSHV contains a Bcl-2 homolog called KSHV Bcl-2 and the protein protects vinis-infected cells from apoptosis.' $\mathrm{KSHV} \mathrm{Bcl-2}$ has four conserved $\mathrm{Bcl}-2$ homology $(\mathrm{BH})$ domains encompassing $\mathrm{BH}-\mathrm{BH}+$ and the presence of $\mathrm{BH} 4$ domain is characteristic of the human anti-apoptotic $\mathrm{Bcl}-2$ family members (Fig. 1). Although KSHV Bcl-2 shares the overall fold as human $\mathrm{Bcl}-2$. its specificity is different from that of human anti-apoptotic $\mathrm{Bcl}-2$ family proteins. ${ }^{2}$ While how the virus mimics host proteins is of great therapentic importance. the mechanism of apoptosis inhibition by KSHV $\mathrm{Bcl}-2$ is largely unknown.

Human p 53 tumor suppressor has been known to induce cell cycle arrest and apoptosis of damaged cells. Aside from its transcription-dependent apoptosis, p53 mediates the mechanism of transcription-independent apoptosis. In response to various apoptotic stimuli. cytosolic p53 moves to the mitochondria and binds to $\mathrm{Bcl}-2$ family proteins. In particular, the interactions of $\mathrm{p} 53$ with the anti-apoptotic Bcl-2 family proteins such as $\mathrm{Bcl}-2$ and $\mathrm{Bcl}-\mathrm{XL}$ were shown to relieve the inhibition of pro-apoptotic Bcl-2 family proteins by them. leading to activation of intrinsic mitochondrial apoptosis pathway. Although it can be speculated that viral $\mathrm{Bcl}-2$ homologs mimic the function of cellular anti-apoptotic $\mathrm{Bcl}-2$ family proteins, any molecular interaction of viral $\mathrm{Bcl}-2$ homologs with p 53 has not been observed to date. In this study: we studied the molecular interaction between KSHV Bcl-2 and 53 TAD by NMR binding experiments.

Figs. 2A and 2B show the $\mathrm{H}^{3}{ }^{3} \mathrm{~N} \mathrm{HSQC}$ spectra for free state and KSHV Bcl-2-bound p53 TAD. respectively. The crosspeaks for free state $\mathrm{p} 53 \mathrm{TAD}$ at $\mathrm{pH} 7.8$ were assigned using the previous assignument obtained at different $\mathrm{pH} .{ }^{4}$ Upon

"These authors contributed equally to this work binding to KSHVBcl-2. the crosspeak corresponding to Lew26 disappeared and the intensity of crosspeaks corresponding to Leu22. Trp23. Ly's24, and Leu25 was greatly reduced. This spectral change seemed to arise from significant line broadening

A Viral Bcl-2 homologs

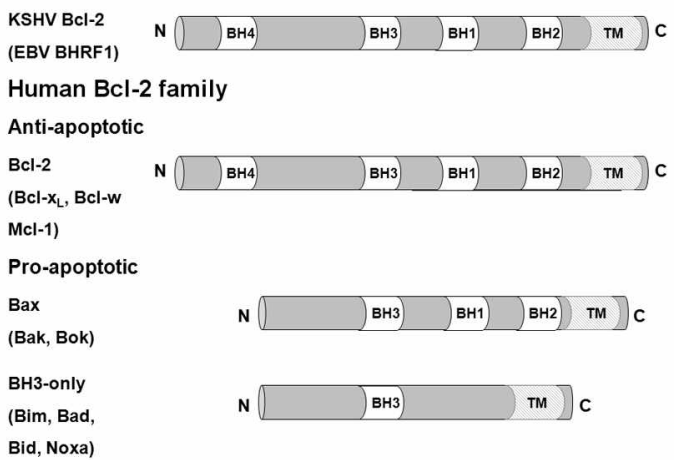

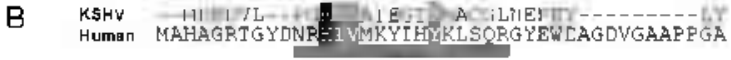
BHA

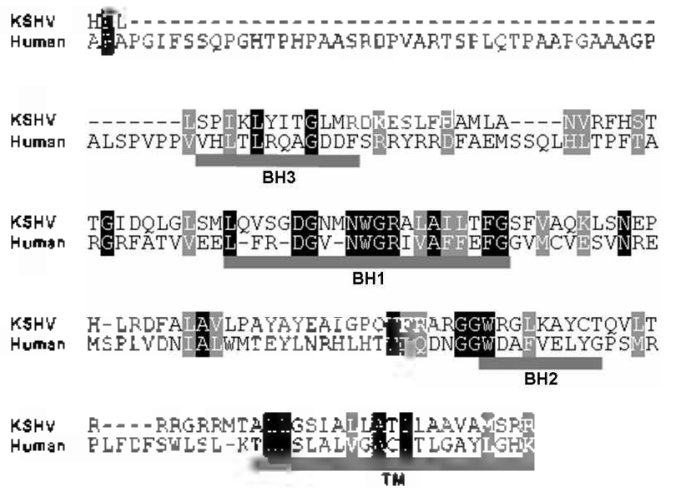

Figure 1. Comparison of domain structure and sequence between $\mathrm{KS} H \mathrm{HV} \mathrm{Bcl}-2$ and human Bcl-2 family proteins (A) Human Bcl-2 family proteins are classified into three subfamilies ( $\mathrm{Bcl}-2$, $\mathrm{Ban}$, and $\mathrm{BH}$-only j. Bcl-2 homology $(\mathrm{BH})$ domains and transmembrane segment (TM) are indicated. (B) Sequence alignment between $\mathrm{KSHV} \mathrm{Bcl}-2$ and human $\mathrm{Bcl}-2$. The BH domains and TM are shown below the sequence. 

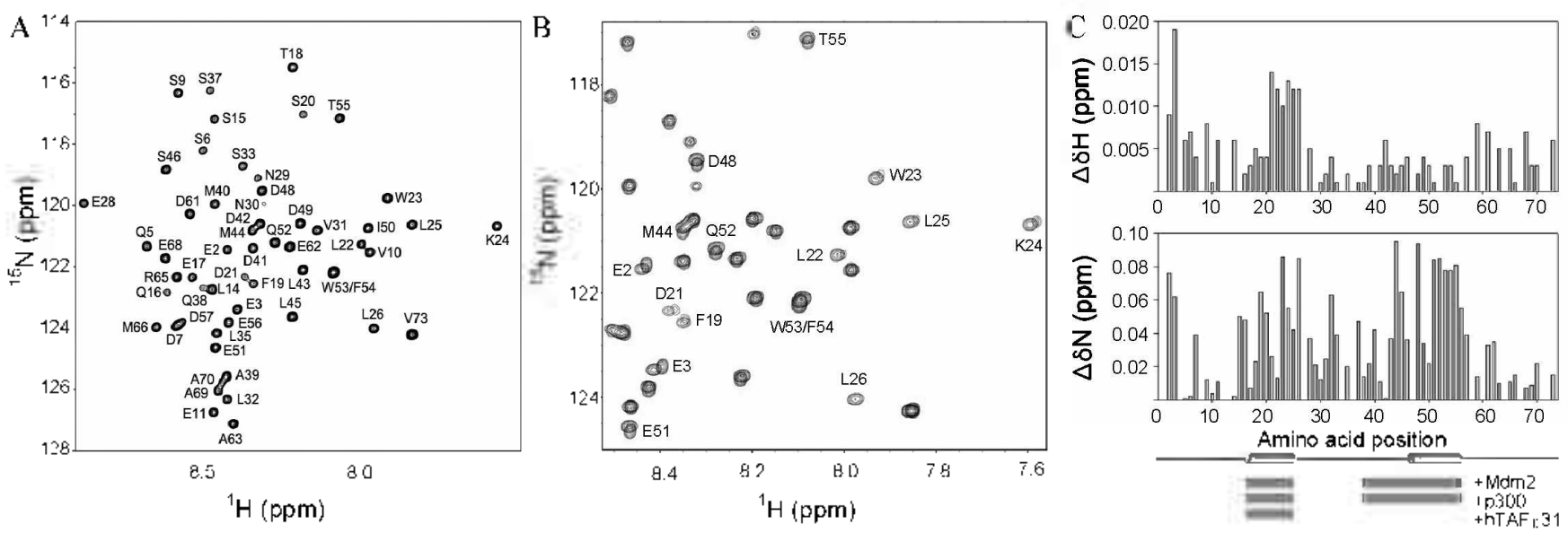

Figure 2. Chemical shift perturbations on p 53 TAD by binding KSHV Bel-2. (A) The 2D ${ }^{15} \mathrm{~N}-{ }^{-} \mathrm{H} H S Q C$ spectrat for lree slate p53 TAD. (B) The overlaid HSQC specta for free state (blue) and KSHV Bcl-2-bound p53 TAD (red). The crosspeaks of p53 TAD residues 1hat showed significant reduction of intensity or chenical shift change upon binding KSHV Bcl-2 are labeled. To observe obvious chenical shifi pertubation. binding titration was performed until the molar ratio of p5.3 TAD to KSHV Bcl-2 reaches 1:4.5. (C) Chemical shift perturbations on p 53 TAD by binding KSIIV Bcl-2 and binding site comparison. Chemical shift changes for ${ }^{1} \mathrm{HI}$ (top) and ${ }^{15} \mathrm{~N}$ frequency (bottom) are plotted against the residue number of p5.3 TAD. For comparison. the siles where significant NMR chemical shift perturbations occurred upon binding indin2. $\mathrm{hTAF}_{13} 31$ or $\mathrm{p} 300$ are displaycd in the bottom. ${ }^{1.78}$ The $\mathrm{cy}$ linders in the bottom indicate the location of $\alpha$-helices found in the structures of mdm2-bound and Tfbl-bound complexes.

due to intermediate chenical exchange on the NMR time scalc (Fig. 2B). This indicates that the residues $22-26$ of p53 TAD are significantly involved in the interaction with $\mathrm{KSHV}$ $\mathrm{Bcl}-2$. Figure 2 shows chemical shift perturbations on 053 TAD upon binding to KSHV Bel-2. Except flexible $\mathrm{N}$-terminal teminal residues 2-3. the largest chenical shift changes were observed at the two regions of p53 TAD encompassing the residues $18-26$ and 44-57. indicating that they form the binding sites for KSHV Bcl-2. Interestingly: the KSHV Bcl-2-binding regions in 553 TAD are well overlapped with the sites where significant chemical shift perturbations occurred upon binding mdm2. ${ }^{4} 3000^{5}$ or hTAF $31^{6}$ (Fig. 2C). Due to difference in binding affinity, the magnitude in chemical shift perturbation for KSHV Bcl-2 is lower that that for ndm2. However. exchange broadening in residues $22-26$ of 553 TAD is common for binding to $\operatorname{mdm} 2, \mathrm{p} 300$ and $h \mathrm{TAF}_{11} 31$. The agreement in the chemical shift perturbation data suggests that the binding of p53 TAD with KSHV-Bcl2 may occur in a manner similar to that with mdm2. p300. and hTAF 3 II. While p53 TAD is strueturally disordered, it is likely that the well-defined amphipathic $\alpha$-helices in the p53 TAD (Fig. 2C). fonned by residues 18-26 and 47-55. mediate hydrophobic interaction with KSHV Bcl-2 as observed in the structures of mom2bound and Tfbl-bound complexes. ${ }^{7.8}$

In this report. we show the first case where the direct interaclion between viral $\mathrm{Bcl}-2$ homolog and p53 is observed. Considering the structural similarity with $\mathrm{KSHV} \mathrm{Bcl-2,} \mathrm{the}$ other viral $\mathrm{Bcl}-2$ lıomologs such as $\mathrm{Ml} 1 \mathrm{~L}$ from myxoma virus max also be involved in the direct interaction with p53 TAD. For cellular $\mathrm{Bcl}-2$ family proteins, in vivo interaction of $\mathrm{Bcl}-2$ and $\mathrm{Bel}-\mathrm{XL}$ with p53 was observed at the cellular level" and the interactions were shown to be mediated via the DNAbinding domain of $553 .^{3.10}$ Recently: Bel-XL was observed to interact with the N-teminal domain of p53." Therefore. it is possible that KSHV Bel-2 prevents the transcription-indepen- dent apoptosis of p53 by interfering with the direct interactions between p53 and cellular anti-apoptotic Bcl-2 family proteins. Dysregulation of the host apoptosis mechanism by viral $\mathrm{Bcl}-2$ homolog mav enhance the survival of the virusinfected host cells. The information on the dysregulated pathway and the binding site should contribute to the development of antiviral therapies.

ln conclusion. we demonstrated direct interaction between KSHV Bel-2 and p53 TAD using NMR binding experiments. Our chemical shift perturbation data determined the KSHV $\mathrm{Bcl}-2$-binding sites on p 53 TAD at the atomic level, indicating that the binding sites coincide with those for mdm2. p300. or $h T A F_{11} 31$. Our observation suggests that the other viral Bcl-2 homologs max be involved in the interaction with p53 as collular Bcl-2 family proteins

\section{Experimental Section}

KSHV Bcl-2 (residues 1-146), in which C-teminal transmembrane segment was truncated and N67D/V 1 17A mutations were introduced. and p53 TAD (residues 1-73) were expressed and purified as previously described. ${ }^{2.4}$ The $2 \mathrm{D}^{15} \mathrm{~V}-1 \mathrm{H}$ I ISQC spectra of ${ }^{15} \mathrm{~N}$. ${ }^{13} \mathrm{C}$-labeled p53 TAD were obtained in the absence or presence of KSHV Bcl-2. All NMR data were acquired at $5^{\circ} \mathrm{C}$ on Bruker Avance 11900 spectrometer equipped with eryogenic probe. N.MR samples containing $50 \mu \mathrm{M}$ ${ }^{15} \mathrm{~N} .{ }^{13} \mathrm{C}$-labeled p53 TAD alone or with KSHV Bcl-2 were prepared in $95 \% \mathrm{H}_{2} \mathrm{O} / 5 \%{ }^{2} \mathrm{H}_{2} \mathrm{O}$. 20 mM TrisHCl, pH 7.8 and $5 \mathrm{mM}$ DTT. All NMR data were processed and analyzed using an ntmrPipe/nmrDraw and SPARKY software. ${ }^{1213}$

Acknowledgments. This study was supported by a grant from the National R\&D Program for Cancer Control. Ministry for Health. Welfare and Family affairs. Republic of Korca (0720130) (to S.-W. C.). This study was also supported by the 
KOSEF Grants (R01-2007-000-10691-0 to J.-H. L.: R0l2008-000-20786-0 to S.-W. C.). the KRF Grant (KRF-2008-331C00178) (to J.-H. L.), and an EB-NCRC grant (R15-2003$012-01001-0$ ) funded by the Korean Government (MEST). This study made use of the NMR facility at KBSI. which is supported by Bio-MR Research Program of the Korean Ministry of Science and Technology (E28070)

\section{References}

1. Sarid, R.: Sato, T.: Bohenzky, R. A.: Russo, T. J. Kat. Med. 1997, 3(3), 293-298

2. Huang, Q.; Petros, A. M.; Virgin, H. W.; Fesik, S. W.; Olejniczak; E. T. Proc. Katl. Acad. Sci. LS.4 2002, 99(6), 3428-3433

3. Tomita, Y:- Marchenko, N.: Erster, S.: Nemajerova, A.: Delnner, A.: Klein, C.: Pan, H.; Kessler, H.: Pancoska, P.; Moll, U. M. $J$. Biol. Chent 2006, 28I(13), 8600-8606.

4. Chi, S. W.; Lee, S. H.; Kim, D. H.; Ahn, M. J.; Kim, J. S.; Woo,
I. Y.: Tonzawa, T.; Kainosho, M.: Han, K. H. J. Biol Chem. $2005,280(46), 38795-38802$

5. Teufel. D. P.: Freund, S. M.: Bycroft, M.: Fersht. A. R. Proc Natl Acad Sci LS. 2007, 104(17), 7009-7014.

6. Uesugi, M. Verdine, G. L. Proc Kat Acad Sci LSA 1999. 96 (26), 14801-14806.

7. Kussie. P. H.: Gorina. S.: Marechal. V: Elentalas. B.: Morean. T.: Levine, A. T.; Pavletich, N. P. Science 1996, 274(5289), 948-953.

8. Di Lello, P.; Jenkins, L. M.; Jones, T. N.; Nguyen, B. D.; Hara, T.: Yamaguchi, H.: Dikeakos, J. D.; Appella, E.: Legault, P; Omichinski, T. G. Mol Cell 2006, 22(6), 731-740

9. Mihara, M.; Erster, S.; Zaika, A.; Petrenko, O.; Chittenden, T.; Pancoska, P.; Moll, U. M. Hol. Cell 2003, H1(3), 577-590.

10. Sot, B.; Freund, S. M.: Fersht, A. R. J. Biol Chem. 2007, $282(40)$, 29193-29200

11. Xu, H.: Tai, I.; Ye, H.; Kang, C. B.; Yoon, H. S. Biochem. Biopins. Res. Commun. 2006, 341(4), 938-944.

12. Bang, J.; Kang, Y.-M: Choi, B.-S.; Lee, T.-H. Bull. Kowem Chem. Soc. 2007, 28(12), 2543-2545.

13. Lee, J.-H. Buhl Korean Chem Soc. 2007, 28(10), 1643-1644. 